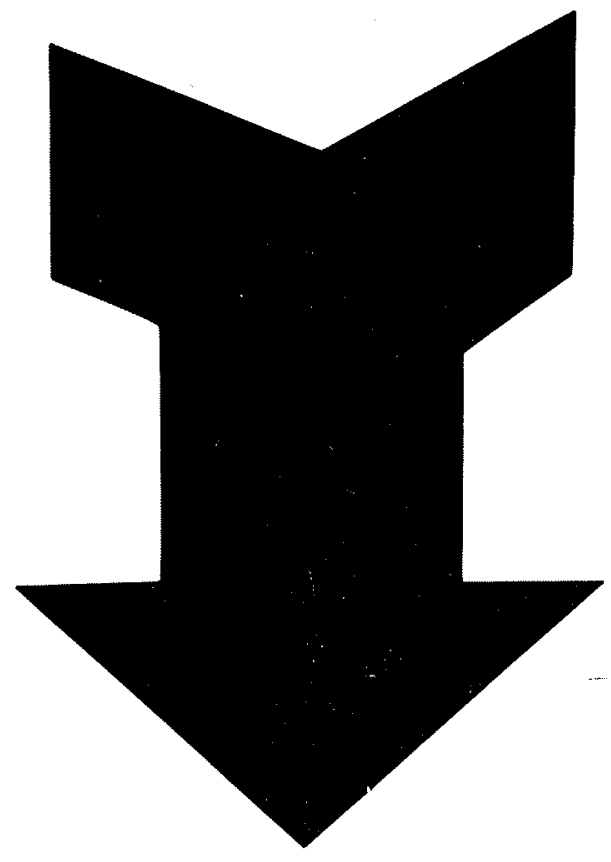

\title{
PHOTOMETRIC COUNTER FOR FLUORESCENT \\ TRACERS
}

BY M. DE VRIES *
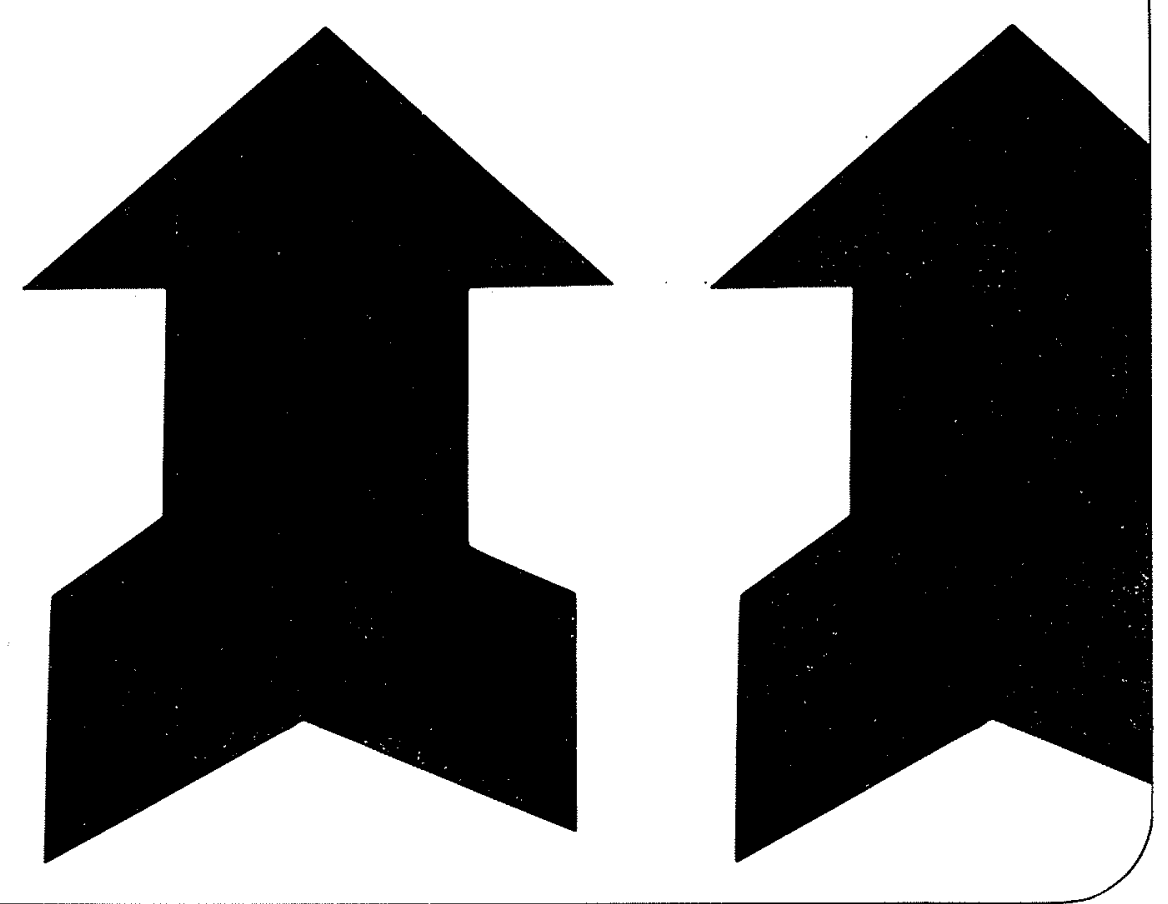

1. Introduction

2. Scope of the study

The development of methods to the quantitative interpretation of measurements with fluorescent tracers for sediment studies, has led to the construction of a special instrument. The instrument has been developed in close contact with the major study on tracers. This contact was essential in order to obtain an optimal solution. The requirements for the instrument were kept to a minimum in order to avoid high expenses for the instrumentation.

The study started in 1963; in 1964 the first instrument was ready for use. After having obtained experience with this prototype, a second improved version was built in 1965 . This instrument has been used for extensive trace-studies. It was found to be satisfactory, if sufficient care is taken with regard to the calibration and maintenance. The development and construction of the instrument has had the continuous care of Mr. H. Mondria of the Instrumentation Department of the Laboratory. The design and the construction of the optical part of the instrument was carried out by the Technisch-Physische Dienst T.N.O.-T.H. in Delft.

* Delft Hydraulics Laboratory, Delft, the Netherlands.
Tracer studies for sediment problems are carried out in order to deduce the transport of sediment from the transport of the tracers. The injection of a certain amount of tracers to a sediment process (i.e. at a river bed or along a coast) makes it possible to follow the dispersion of the tracers at various locations near the point of injection.

Under certain circumstances a quantitative determination of the transported sand is possible. A method has been developed to describe the dispersion of tracer-particles theoretically. Measured concentrations (by weight or volume) are needed to derive the sediment-transport with the help of the theoretical dispersion by means of the leastsquares method [1]. The main problem for the instrumentation is therefore to determine the tracer concentration at various places with sufficient accuracy.

At present the following rough distinction can be made.

1. Radio-active tracers provide the direct measurement in situ. An instrument can be dragged over the river-bed or the sea-bottom. There has not been achieved a full proof method for the measuring of the real local concentration;

2. Fluorescent tracers provide not the direct measurement in situ, though development of such a method is not excluded. Samples have 


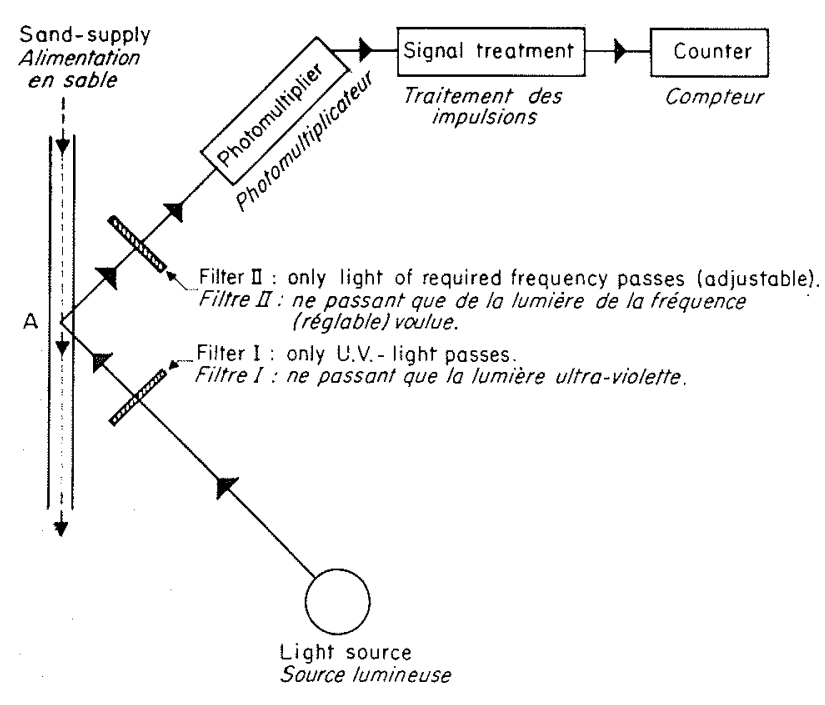

1/ Principle of electronic counter. Principe du compteur électronique.

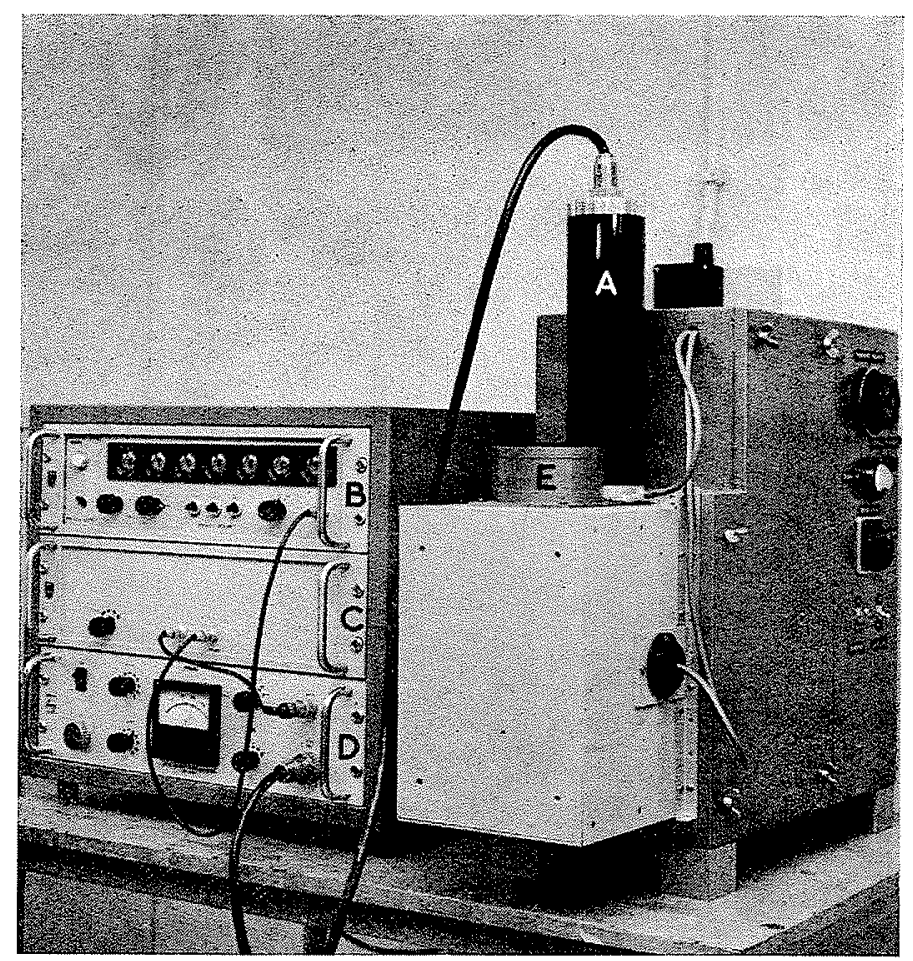

2/ The electronic counter A: photomultiplier; B: counter; C: amplifier; D: high voltage supply; E: ventilator).

Le compteur électronique (A: photomultiplicateur; $B$ : compteur; $C$ : amplificateur; $D$ : alimentation $\dot{a}$ hante tension; $E$ : ventilateur). to be taken from the river-bed or the sea-bottom. Quantitative analyses ashore are possible.

Naturally, adequate sampling is required. For the quantitative analysis described in this report these samples are supposed to be available and the question can be put how to analyse these samples in order to derive the tracer-concentration with sufficient accuracy. There is no need to require extremely large accuracy for the actual determination of the tracer concentration, as the sampling itself introduces inaccuracy [1]. This question will be treated in paragraph 4 .

One aspect has to be discussed in addition. Mostly tracer-tests are requested for non-uniform sand. Thus sand of different grain-sizes is taking part in the transport-process. A correct quantitative tracer-test requires the concentration for the various grain-sizes separately, unless the sand can be considered almost uniform. Moreover, it must be possible to inject tracers at more than one place at the same time. In that case the concentration has to be measured for each injection-point separately. This includes that a twofold discrimination. is necessary at the same time.

a) discrimination with regard to the grain-size;

b) discrimination with regard to the source of the tracers.

The main requirements for the instrument are:

1. Quick determination of the tracer-concentration with sufficient accuracy;

2. Grains of various sizes must be handled;
3. Discrimination with regard to the grain-size has to be possible;

4. Discrimination with regard to the origin of the tracer must be possible.

These requirements are fulfilled as follows. Sieving of samples can be carried out without large costs. Therefore the complexity of the instrument can be reduced considerably if the determination of the concentration takes place only after sieving. The discrimination of the origin of the tracers can be carried out by using different colours.

A choice had to be made in advance between two principle possibilities:

a) This discrimination is carried out at the same time: Therefore the instrument has to be equipped with various channels, each adjusted for a specific colour;

b) This discrimination is not carried out at the same time. The measurements are taken for the various colours after each other, i.e. by making the one-channel instrument adjustable for various colours.

After studying these possibilities the second one has been chosen.

\section{Set-up of the instrument}

The photometric counter consists mainly of three parts (fig. 1): 


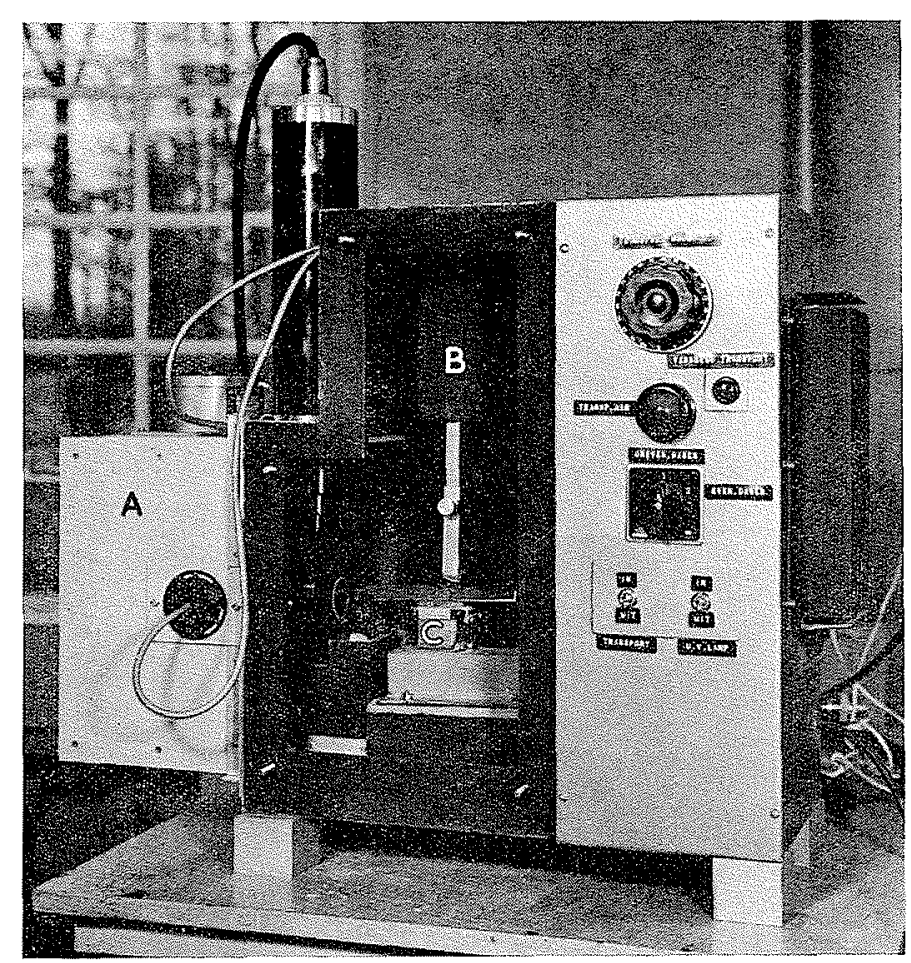

3/ The mechanical supply system (A: optical system; B: labyrinth; $\mathrm{C}$ : vibrator).

Dispositif d'alimentation mécanique (A: système optique; $B:$ labyrinthe; $C:$ vibreur).

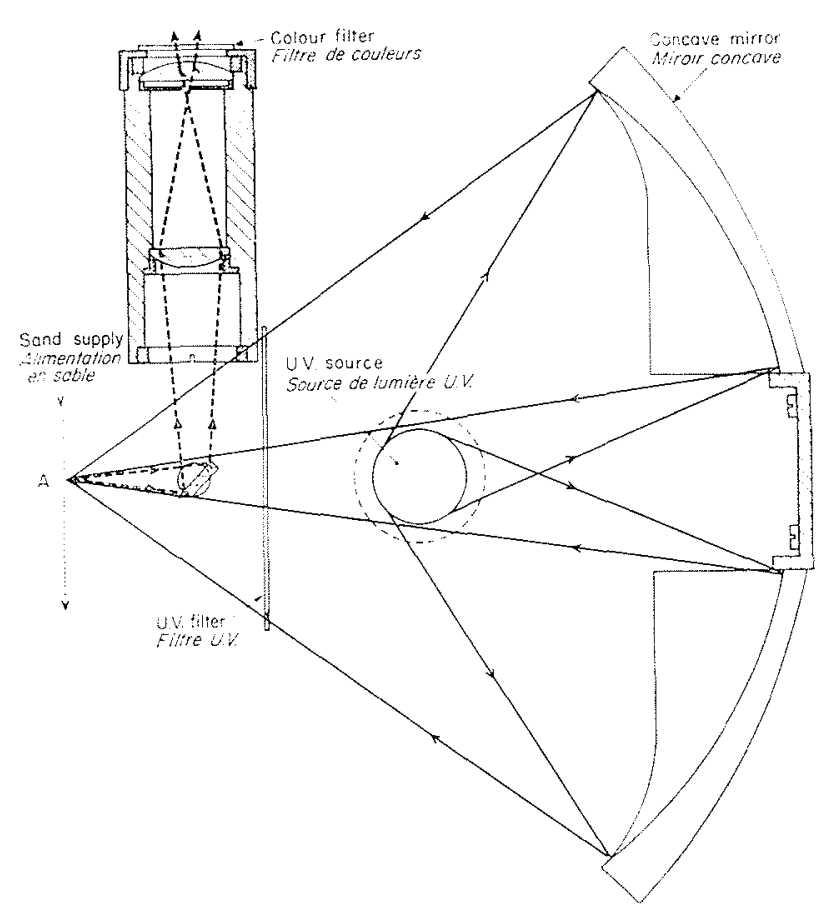

4/ Optical system.

Système optique.
1. Mechanical supply-system;

2. Optical system;

3. Electronic system for signal treatment.

The mechanical supply-system provides the transport of the (uniform) grains of a sample. The sand arrives at the location $A$ where it enters the optical system.

The optical system can be divided into two parts. The first part focusses ultra violet light at the location $A$ in order to radiate the tracers present. The second part focusses the fluorescent light on the photomultiplier B.

The electronic system treats the signals generated at the photomultiplier into an adequate reading.

The instrument consists of two boxes (fig. 2). The mechanical and optical system are constructed in a black box. The electronic equipment is assembled in a separate box.

The aim of the mechanical system is to transport the grains of the sample to the spot $A$ where radiation takes place. In principle the grains have to reach $A$ one after each other. However, as usually small concentrations are concerned

$$
\left(10^{-6}<\mathrm{C}<10^{-3}\right)
$$

a layer of more than one grain thickness is also acceptable.

The mechanical system consists of a vertical tube (Fig. 3) transporting the sand to one end of a small vibrating flume. The grains leave this flume in free fall. During this free fall the grains obtain higher velocities. However, due to collisions the thickness of the sand curtain increases. Therefore the location of A should not be chosen too far below the end of the flume.

The transport of the grains can be increased if the amplitude of the vibration is enlarged. For an adjusted location $A$, however, the layer of sand becomes thicker.

The construction of the optical system is represented in figure 4 . The light of the U.V.-source (Philips H.P. $125 \mathrm{~W}$ ) is concentrated via a concave mirror and through a U.V.-filter on the spot A.

The fluorescent light generated at the tracers is reflected in a vertical direction by means of a small flat mirror. This light is focussed by a system of two lenses and a diaphragm through an (adjustable) colour-filter on the photomultiplier.

The characteristics of the various components had to be balanced, viz.

a) the spectral distribution of the U.V.-source (Fig. $5 c$ ) ;

b) the characteristics of the U.V.-filter (Fig. $5 \mathrm{~b}$ );

c) the spectrum of the fluorescent light;

d) the characteristics of the colour filter (Fig. $5 d$ );

e) the spectral sensitivity of the photomultiplier (Fig. $5 a$ );

Two precautions are taken. Firstly no light may enter the black box from outside, as this may meet the photomultiplier via reflection (therefore the 


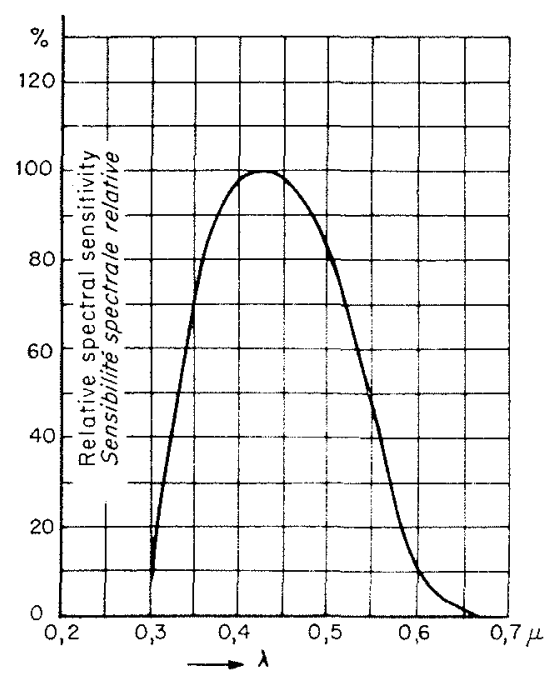

a) PHOTONULTIPLIEA

PHOTOMULTIPLICATEUR

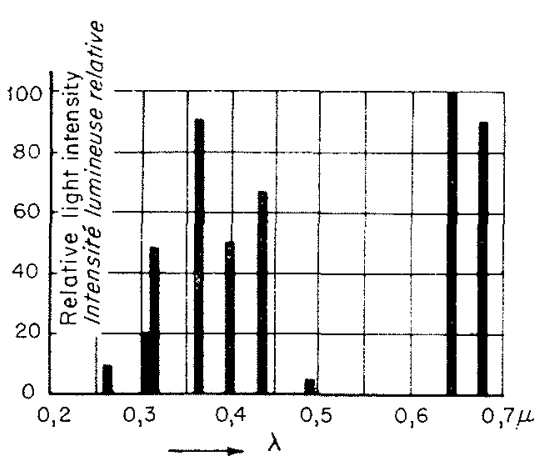

c) U.V. SOURCE

SOURCE DE LUMIERE U.V.

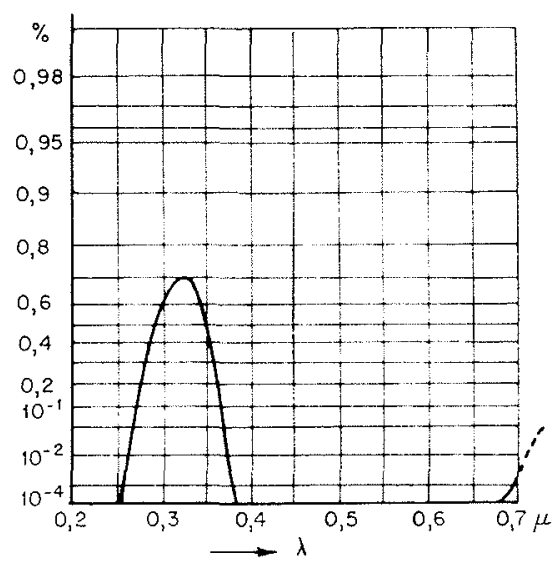

D) U.V. FILTER
FILTRE U.V.

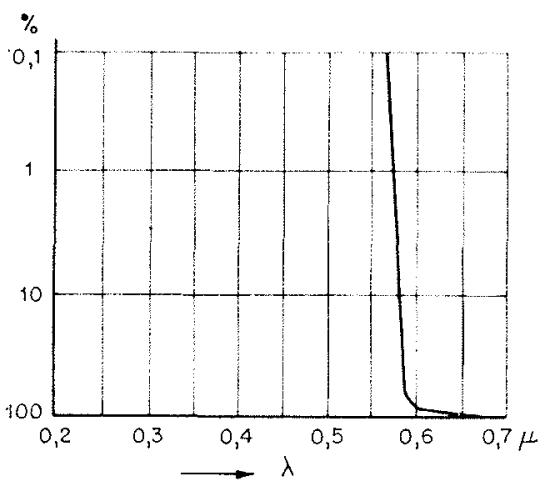

d) COLOUR FILTER (RED)
5/ Characteristics of various components Caractéristiques de divers éléments.

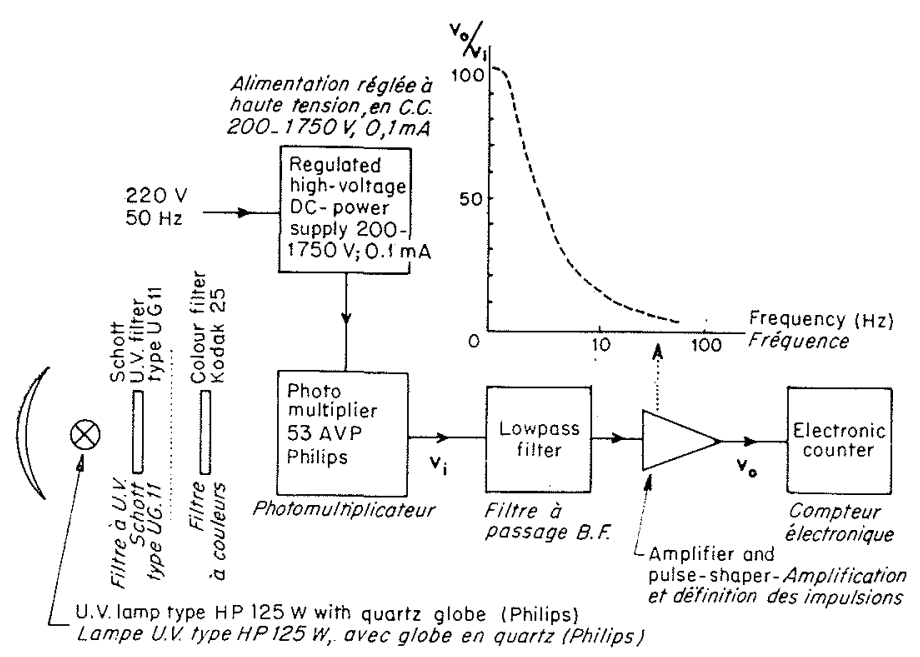

6/ Signal treatment.

Traitement des impulsions.

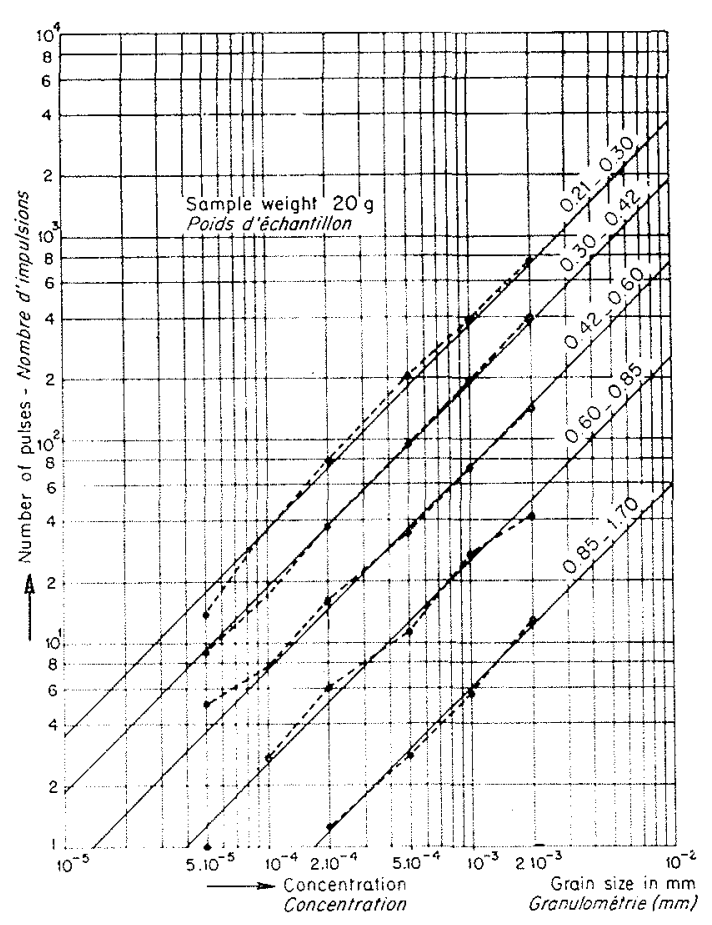

7/ Example of calibration curves. Exemple de conrbes' d'étalonnage. 
supply- and discharge-channels for the samples had to be constructed as a labyrinth).

Secondly the light of the U.V.-source may only be applied to the generation of fluorescent lighting of the tracers. It may not enter the photomultiplier (requirements for the colour filter).

Therefore blueish tracers are not very attractive as they require very sharp filters (U.V.-filter and colour filter). On the other hand the sensitivity of the photomultiplier decreases in the direction of red colours.

The combination given in Figure 5 has been used for a red tracer having a broad spectrum. This tracer is not very expensive as it can be made with a commercially available paint. When the colourfilter was adjusted, a green tracer also yields reasonable results. In general it can be stated that if many colours have to be used simultaneously, tracers and filters will become more expensive. This question, being part of the tracer study as such, will not be discussed here.

Some additional remarks about the optical system can be given

a) the U.V.-source is put in series with a resistance of about $100 \Omega$. The supply is an A.C.current $(220 \mathrm{~V}$ and $50 \mathrm{~Hz})$, rectified into a pulsating D.C.-current. During the operation the source is supplied with about $125 \mathrm{~V}$, due to the presence of the resistance. The initial voltage is higher (about $220 \sqrt{2} \mathrm{~V}$ ), sufficient to ionizate the gas in the U.V.-source;

b) a ventilator is adjusted to cool the U.V.-source. Besides this provision it was necessary to construct the U.V.-filter piece by piece supported by a copper frame. The heat generated in those pieces is thus removed by the metal. Previous construction of the U.V.-filter is one piece has led to destruction of the filter by heat.

The signal treatment is demonstrated in Figure 6. The pulse of each grain is differentiated in the photomultiplier. After filtering, the pulse is amplified and counted. As only a positive voltage is counted, each grain is only counted once. Figure 5 gives the characteristics of filter and amplifier.

The maximum permissible voltage for the photomultiplier amounts to $1700 \mathrm{~V}$. A high voltage leads to spontaneous counting due to light of the U.V.-source that may be caught by the photomultiplier under these circumstances. A low voltage does not give pulses of sufficient amplitude for the tracers. A voltage of about $1200 \mathrm{~V}$ is an attractive optimum. The sensitivity of the instrument can be changed by the amplification of the amplifier.

For the present situation the $100 \mathrm{~Hz}$ noise, generated by the U.V.-source can not be suppressed sufficiently by the filter. This is due to the fact that this frequence is too close to the frequence (about $25-50 \mathrm{~Hz}$ ) of the falling tracers. The distinction can be made in the present set-up, as the amplitude is only $1 / 5$ th of the amplitude of the tracerpulses. The purpose is to increase the frequency of the AC current for the U.V.-source. Increase of the frequency of the falling tracers is more difficult, as a layer of one grain thickness has to be produced as good as possible. In principle it is possible to get the readings punched.

\section{Calibration}

Before the calibration of the instrument can be discussed, attention should be paid to the errors possible in the concentration determined. The source of the errors are mainly [1]:

1. Due to the fact that the sample-size is restricted the concentration determined has some inaccuracy (sampling-error);

2. The quality of the tracers may not be ideal: part of the sand may have a poor coating (coating errors);

3. The counter may introduce some errors: repeated reading of the same sample may give different results (error of counter-efficiency);

4. The number of grains is counted by the instrument, the concentration is only obtained by converting this number into weight or volume. This introduces errors, as the sample does not exist of uniform spheres ("conversion-errors").

From the view-point of the instrument, the following remarks have to be made. The samplingerror can not be reduced by the improvement of the instrument. Only increase of the sample size and/or using higher concentrations for the tracer tests can give improvement of the final results.

The coating-errors may be reduced by using better (i.e. more expensive) tracers or by increasing the sensitivity of the instrument. The error of counter-efficiency can be improved by constructing a better instrument or by reduction of the rate of sand-supply.

The conversion-errors can only be reduced if more uniform sand is handled. This can be done by using a $\sqrt{2}$-series of sieves instead of a $\sqrt{2}$ series. Naturally this enlarges the amount of work for tracer-tests. The sampling errors and the conversion-errors can be related to the number or tracer-particles $\mathrm{X}$ present in the sample [1].

The following relative errors $r_{C}$ are present:

- sampling error:

$$
r_{\mathrm{C}_{1}}=\mathrm{X}^{-1 / 2}
$$

- conversion error:

$$
r_{C 2}=\beta \mathrm{X}^{-1 / 2}
$$

with $\beta \approx 0.7$ for natural sand ( $\sqrt{2}$-series sieves).

The coating errors and the error of counterefficiency are present in the readings of the instrument.

If :

$$
\mathrm{Y}=\alpha \mathrm{X}
$$

relates the number of tracer-particles $\mathrm{X}$ with the number of pulses $\mathrm{Y}$ then:

$$
r_{\mathrm{C}_{3}}=r_{a^{\prime}}
$$

can be found from calibration tests with ideal tracers.

In practice the coating-errors will influence the reading $Y$ and therefore the $r_{a}$ found from the instrument will be influenced by coating errors as well. 
The total error present in the concentration derived will be:

$$
r^{2}{ }_{\mathrm{C}}=\sum r_{\mathrm{C}_{i}}=\left(1+\beta^{2}\right) \mathrm{X}^{-1}+r^{2}{ }_{\alpha}
$$

The first terme of (5) is mainly dominant. Therefore relatively large values of $r_{a}$ are acceptable (roughly 0.05 to 0.10 ) before $r_{a}$ becomes important for the total inaccuracy.

From the practical point of view, it is attractive to relate the reading of the instrument (number of pulses) directly to the concentration. Therefore, the instrument has to be calibrated by determining the readings for known concentrations and not for known numbers of tracers!

The calibration is carried out for standard-concentrations. For each sample 10 readings $\mathrm{Y}$ are mainly taken and the average value $\bar{Y}$ is taken and plotted against $C$.

Figure 7 gives an example for various size-fractions. The variations of the measurements round the straight lines are mainly caused by the "conversion-errors", as each point is taken from one specific sample. The fitting of the lines reduces the influence of the number $\mathrm{X}$ of the grains incidentally present in the sample.

The main factors influencing the calibration are:

a) the voltage of the photomultiplier;

b) the amplification;

c) the age of the U.V.-source;

d) the cleanliness of the mirrors.

The last two factors cause the need for regular calibration. Control of the calibration curve by some test-samples gives the possibility to decide whether a new calibration is needed.

Reference

[1] M. de Vures. - Applications of luminophores in sand transport studies. Thesis Delft, publ. 39, Delft Hydr. Lab. (May 1966), 86 p.

\title{
Résumé
}

\section{Compteur photométrique pour traceurs fluorescents}

\author{
par Mu de Vries *
}

L'auteur décrit la construction d'un appareil nécessaire pour la détermination de la concentration en traceur dans des échantillons prélevés sur le fond d'une rivière, après injection de traceur. Dans certaines conditions, il est possible d'effectuer une détermination quantitative du débit solide par charriage [1], mais à condition de disposer des valeurs mesurées de la concentration.

L'appareil comporte 3 parties : le système mécanique assurant l'alimentation correcte du sable (photo 3), le système optique créant la fluorescence des traceurs (fig. 4), et le système électronique traitant l'impulsion provenant d'un photomultiplicateur en une indication adéquate (fig. 2).

L'appareil est conçu pour le traitement d'échantillons à granulométrie uniforme, puisque le débit solide correspondant à chaque fraction granulométrique doit être déterminé séparément. Il a été porté une attention toute particulière à la précision nécessaire de l'appareil. L'erreur sur la concentration découle avant tout des dimensions limitées de l'échantillon (équation 1), et de la transformation du nombre d'impulsions en valeurs de concentration en fonction du poids, ou du volume (équation 2). Quelques exemples de courbes d'étalonnage sont donnés sur la figure 5. 